\title{
"Mas quem ia carregar uma nota fiscal?": uma investigação da função modal de mas em língua portuguesa
}

\section{"Mas quem ia carregar uma nota fiscal?": an investigation on the modal function of mas in portuguese}

\author{
Marceli Cherchiglia Aquino* \\ Ana Laura Macruz Cinto** \\ Tamires Arnal Kahil***
}

\section{RESUMO}

Com o presente trabalho propomos uma investigação inicial acerca da categorização de mas como partícula modal (PM), adequando a sua classificação nas gramáticas do português brasileiro. Nosso principal objetivo foi, portanto, levantar hipóteses sobre a função modal da PM mas, identificando quais pressupostos são ativados por meio de seu uso, diferenciando-a de seu homônimo, a conjunção adversativa. Para auxiliar o estabelecimento de uma classe de palavras modais em português, partimos de uma investigação contrastiva com a língua alemã, que possui uma categorização homogênea das PMs. Como suporte a esse estudo, adotamos contextos de uso autênticos apoiados em tirinhas em língua portuguesa e alemã, contendo a PM mas, a conjunção mas e a PM alemã aber. Tal investigação permitiu delimitar a função

Recebido em 15 de maio de 2020.

Aceito em 9 de setembro de 2020.

DOI: http://dx.doi.org/10.18364/rc.v1i60.414

*Universidade de São Paulo, marceli.c.aquino@gmail.com, orcid.org/0000-0003-0518-7639

**Universidade de São Paulo, ana.cinto@usp.br, orcid.org/0000-0003-2034-6191

***Universidade de São Paulo, kahiltamires@gmail.com, orcid.org/0000-0001-7426-1375

Confluência. Rio de Janeiro: Liceu Literário Português, n. 60, p. 373-399, jan.-jun. 2021 
modal da partícula mas, evidenciando a importância de estudos inclusivos para a identificação de uma classe de palavras modais no português brasileiro.

Palavras-chaves: palavras modais em língua portuguesa; a partícula modal mas; análises contrastivas.

\begin{abstract}
In this work, a preliminary investigation regarding the classification of mas (but) as a modal particle (MP) in Brazilian Portuguese is presented. Our main purpose is to pose hypotheses concerning the modal function of the MP mas, aiming to identify the semantic and pragmatic differences of this modal word from its non-modal homonym, the adversative conjunction. To support our study, we performed a contrastive investigation with German, where MPs have a homogenous categorization. In particular, we adopted authentic contexts of usage provided by comics in Brazilian Portuguese and German containing the MP mas, the conjunction mas and the German MP aber. This investigation allowed us to narrow down the modal function of the particle mas, emphasizing the importance of inclusive studies in order to identify a class of modal words in Brazilian Portuguese.
\end{abstract}

Keywords: modal words in Portuguese; mas as modal particle; contrastive analysis.

\title{
Introdução
}

A Teoria dos Atos de Fala (AUSTIN, 1962/1990) emergiu como reação à semântica das condições de verdade (truth-conditional semantics), que postulava que uma frase, ou segmento linguístico, seria significativo apenas se pudesse ser avaliado em termos de verdade ou falsidade. Para Austin, o uso da linguagem verbal não descreve somente a realidade, produzindo assertivas verdadeiras ou falsas, mas também tem a capacidade de alterá-la e, até mesmo, criar novas realidades. Segundo essa vertente, os segmentos linguísticos podem estabelecer duas categorias de entidades linguísticas, a frase e o enunciado. As frases seriam puramente constatativas, tendo relação com as condições de verdade (veracidade ou falsidade dos estados de coisas descritos), enquanto os enunciados seriam performativos, que implicam as condições de felicidade (a realização de uma determinada ação) (AQUINO, 2016, p. 35). 
Assim, a análise da linguagem nessa nova vertente tem como evidência as condições de felicidade de um ato de fala, uma investigação a partir das escolhas adequadas dentro de determinados contextos de uso. A modalidade se encaixa nesta perspectiva, no sentido que, os enunciados devem ser considerados dentro das circunstâncias e da função comunicativa de sua produção. Segundo Palmer (1986, p. 16), a modalidade pode ser definida como a "gramaticalização das atitudes e opiniões do falante". Desta maneira, ela deve ser examinada do ponto de vista da pragmática linguística tendo em vista a situação e a função da enunciação (AQUINO, 2016, p. 36).

Ao utilizar formas modais, como é o caso das partículas modais (PMs), o falante participa da enunciação, indicando o seu engajamento com o que é expressado, isto é, ela qualifica o seu comprometimento sobre a proposição. Para Leiss (2012, p. 41), a modalidade pode ser compreendida como meio linguístico que auxilia na negociação de uma representação mental. A autora afirma ainda que as PMs constituem as funções mais complexas da modalidade, já que com o seu uso o falante é envolvido em um design intrincado de negociação dos diferentes ambientes cognitivos. ${ }^{1}$ Assim, ao utilizar uma PM o falante enfrenta o desafio de encontrar a informação mutuamente manifestada ${ }^{2}$ e convida o ouvinte a compartilhar um conhecimento. Segundo Polenz (1985, p. 195), "os componentes modais e pragmáticos são imprescindíveis para o entendimento do texto enquanto ato comunicativo, e para questionamentos durante a leitura nas suas entrelinhas".

1 Sperber e Wilson (2005, p. 250) definem contexto como conjunto de premissas usadas na interpretação de um enunciado. Neste sentido, o contexto seria um construto psicológico, um subconjunto das suposições do ouvinte acerca do mundo. Este conjunto de suposições do processo comunicativo constituem o ambiente cognitivo.

2 Para a Teoria da Relevância (SPERBER; WILSON, 2005), a manifestação mútua concretiza-se através de um comportamento ostensivo-inferencial entre interlocutores, onde o falante apresenta uma intenção comunicativa (algo a ser comunicado) e uma informativa (o conteúdo a ser comunicado). Para que o processo de comunicação aconteça, o ouvinte precisa ter explicitamente manifesto no seu ambiente cognitivo a intenção comunicativa do ouvinte, a fim de interpretar a respectiva intenção informativa.

Confluência. Rio de Janeiro: Liceu Literário Português, n. 60, p. 373-399, jan.-jun. 2021 
As PMs são, portanto, marcadores de funções pertencentes aos domínios da coesão comunicativa e interpessoal (relação ouvinte-falante), por isso o contexto comunicativo em que elas aparecem é tão relevante para seu entendimento (AQUINO, ARANTES, 2020, p. 168). Ao utilizar uma PM, torna-se possível negociar inferências entre os interlocutores, tais como reconhecer a atitude e intenção do falante e as expectativas do ouvinte. Nesse sentido, a necessidade de funções modais nas línguas pode ser postulada pela simples suposição sobre a natureza da comunicação humana (WALTEREIT, 2001: 1399-1400), isto é, a necessidade de meios linguísticos para acessar informações contextuais e compreensão de implicaturas.

A classe de palavras das PMs foi intensamente investigada nas línguas germânicas, mas a existência desses elementos lexicais parece não ser exclusiva do idioma alemão, sendo encontrada também, mesmo contrariando alguns autores alemães, em língua portuguesa (SAID ALI, 1930; KRÖLL, 1968; SCHMIDT-RADEFELT, 1993; WELKER，1990; FRANCO，1991; JOHNEN, 1997; RAMOS, 2000; VILELA; KOCH, 2001; TRAUGOTT, 2007; WALTEREIT, 2007; AQUINO, 2012; 2016; 2018; 2020; DIEWALD, 2013; FISCHER; ALM, 2013; ARANTES, 2017; AQUINO, ARANTES, 2020). Esses teóricos assumem a existência de PMs nas línguas como o catalão, croata, francês, inglês e português, abrindo espaço para abordagens inclusivas e análises situadas em contextos de usos. Essas abordagens certamente apresentam tendências importantes e têm sido destaque na literatura, sobretudo porque propõem uma nova classificação desses elementos modalizadores em outras línguas além do alemão (AQUINO, ARANTES, 2020, p. 180).

Nesse artigo, temos a intenção de analisar a função modal da PM mas, a fim de refletir acerca da necessidade de uma classificação adequada das PMs no português brasileiro. Para tanto, desenvolvemos uma investigação em um corpus de seis tirinhas, quatro em língua portuguesa (Armandinho, Alexandre Beck) e duas em língua alemã para a análise contrastiva com a PM aber (Haiopeis, Thomas Siemensen). A fim de delimitar a função modal de mas, realizamos uma análise contrastiva com o seu homônimo não modal 
(conjunção adversativa) e, com a PM aber, identificando o seu equivalente funcional em língua alemã (AQUINO, ARANTES, 2020, p. 180-182). Vale ressaltar que essa proposta é muito relevante para os estudos linguísticos em língua portuguesa, sobretudo porque as PMs são estratégias comunicativas frequentes na linguagem oral e escrita, mas que ainda não possuem uma classificação adequada nas gramáticas normativas da língua.

Nas próximas seções procuramos estabelecer uma base teórica para a nossa investigação e, posteriormente, apresentamos a análise da PM mas por meio de exemplos retirados de tirinhas em português e alemão. Finalmente, realizaremos uma discussão acerca da função modal nuclear da PM mas e da necessidade de uma adequação de classificação das palavras modais em português brasileiro.

\section{Arcabouço teórico}

As PMs em língua alemã ${ }^{3}$ formam uma classe de palavras homogeneamente definida, sendo classificadas como: não flexionáveis; não acentuáveis; não negáveis; não respondem perguntas (sim e não); são combináveis com outras PMs; não formam um enunciado sozinhas; apresentam função nuclear; estão sintaticamente e gramaticalmente integradas na sentença; posicionadas no campo central da oração (Mittelfeld); ocorrem em tipos específicos de sentenças; têm escopo sobre toda a sentença; ocorrentes em linguagem falada e escrita; apresentam homônimos não modais em outras categorias; têm sentido inferencial (AQUINO, 2020, p. 139). Além disso, as PMs atribuem o máximo de informação com menor esforço cognitivo; especificam a relação entre falante e ouvinte (AQUINO, 2018, p. 269); referem-se a um acontecimento anterior que pode ser recuperado contextualmente (DIEWALD, 2006, p. 406); indicam significados afetivos (DEGAND; CORNILLIE;

3 As 15 PMs mais frequentes : aber, auch, bloß, denn, doch, eben, eigentlich, etwa, halt, ja, mal, nur, schon, vielleicht, wohl (DUDEN, 2016, p. 602). 
PIETRANDREA, 2013: 14-15). Diewald (2013, p. 22) afirma ainda que as PMs são modos de introduzir implicações, suposições e alusão de maneira implícita, e que este potencial é a razão de sua riqueza comunicativa.

Na perspectiva da Teoria da Mente (ToM), a habilidade linguística das PMs de identificar as informações contextualizadas e acessar o ambiente cognitivo entre os interlocutores é chamada de deslocamento duplo (ABRAHAM; LEISS, 2012, p. 11). De acordo com os postulados dessa teoria, os falantes abrem espaço para que os ouvintes avaliem o sucesso da enunciação, negociando significados e produzindo sentidos. Logo, as partículas são meios retóricos para comunicar uma mensagem eficiente e concreta entre os indivíduos envolvidos no processo interpretativo. Portanto, as PMs se destacam por serem elementos complexos com um status ilocutório único, com um grande impacto gramatical e discursivo.

Mesmo com definições bem delineadas acerca das funções comunicativas e da classe de palavras desses elementos em língua alemã, a sua identificação ainda é desafiadora. Essa dificuldade advém, pelo menos em parte, da existência de homônimos não modais como advérbios, adjuntos, partículas escalares e adversativas e interjeições (ABRAHAM 1991, p. 252). Da mesma maneira que em alemão, as PMs em língua portuguesa apresentam características distintas de seu homônimo, possuindo aspectos semânticos, sintáticos e pragmáticos próprios. Segundo Abraham (1991), as PMs derivam diacronicamente de elementos lexicais através da perda de complexidade semântica, mas ganho de complexidade pragmática. Como vamos argumentar com os resultados da análise (seção 4), defendemos que, mesmo com uma estrutura sintática diferente do alemão (como a posição de ocorrência na oração), o português brasileiro possui palavras modais com categorias delimitadoras semelhantes, justificando a adequação de sua classificação gramatical.

Segundo Vilela (1999, p. 263), há no português "partículas modais típicas", as quais se referem ao conteúdo frásico total, "transportando um juízo de valor por parte do enunciador" ou se limitando a certas sequências importantes da frase. Para o autor, mas é um candidato a integrar essa 
categoria, exprimindo "espanto", "surpresa". Nesse caso, vamos além da sugestão de Vilela (1999) para compreender a função de mas que não está restrita à expressão de surpresa ou espanto, mas também para antecipar um conteúdo proposicional que os interlocutores compartilham.

Aquino e Arantes (2020, p. 181) apresentam um exemplo de uso da PM mas através da seguinte situação: alguém veste um casaco sujo para sair de casa e, à porta, o seu interlocutor diz: "mas o seu casaco está todo sujo!". O locutor não apenas expressa surpresa com o fato de o ouvinte intencionar sair com o casaco sujo, como também ressalta que essa informação é compartilhada entre eles: você sabe que o casaco está sujo e, mesmo assim, está querendo sair com ele. O fato de o casaco estar sujo é conhecido, no entanto, com o uso da PM é possível trazer pistas contextuais, como por exemplo: o casaco está muito mais sujo do que os interlocutores poderiam imaginar/lembrar, e quando estão prestes a sair de casa, percebem que é necessário trocar a peça (AQUINO, ARANTES, 2020, p. 181). Para a interpretação do conteúdo enunciativo como PM é essencial, portanto, a análise da função nuclear, assim como do contexto e das intenções comunicativas entre interlocutores (AQUINO 2017: 174).

Ainda segundo Aquino e Arantes (2020, p. 182), assim como a PM mas, a PM alemã aber também indica uma quebra de expectativa ou surpresa. Hentschel e Weydt (2013, p. 289) apresentam uma análise comparativa entre a PM e a conjunção aber, na qual a conjunção tem a função de ligar dois elementos $\mathrm{x}$ e $\mathrm{y}$, de x pode variar uma sequência $\mathrm{z}$ que não é verdade, como "Ellen ist klein, aber stark", ${ }^{4}$ isto é, pelo seu tamanho (x) imagina-se que ela não teria força (z), mas não é verdade, ela é forte (y). A PM aber não apresenta a função de ligar elementos da frase, mas tem escopo na oração toda, como é possível observar no exemplo "Das Wasser ist aber warm!". 5 Uma análise contextual poderia indicar que o falante não esperava que a água estivesse tão quente. A PM aber indica uma surpresa com relação não

\footnotetext{
4 Hellen é pequena, mas forte.

5 Mas que água quente!
}

Confluência. Rio de Janeiro: Liceu Literário Português, n. 60, p. 373-399, jan.-jun. 2021 
apenas ao fato de a água estar quente, já que isso poderia ser esperado, por exemplo, no caso de ligar um chuveiro, mas a quão aquecida ela se encontra (AQUINO, 2020, p. 141).

No presente estudo propomo-nos a investigar, em contextos de uso, o significado e intenção comunicativa da PM mas em língua portuguesa, assumindo uma abordagem minimalista, isto é, considerando que cada PM tem uma função nuclear que modifica a sentença, expressando diferentes graus de intensidade ao conteúdo enunciativo como um todo. Alguns estudos (FRANCO, 1991; SCHMIDT-RADEFELDT, 1993; VILELA; KOCH, 2001) reconhecem que mas, dependendo do uso contextualizado, pode apresentar um caráter modal em português, diferenciando-se de seu homônimo (conjunção adversativa). No entanto, não encontramos essa classificação em gramáticas normativas do português, o que indica a necessidade de uma discussão teórica que confronte as descrições encontradas até o momento. É preciso, portanto, investir em um quadro de descrição pragmática das línguas falada e escrita, para que se reconheça as PMs no português brasileiro. A seguir apresentamos a investigação da função modal da PM mas em um corpus de tirinhas, contrastando as suas características semânticas e sintáticas com o seu homônimo não modal e o equivalente funcional em língua alemã.

\section{Materiais e métodos}

Considerando que este artigo investiga as PMs, que são meios retóricos complexos com um status ilocutório único, foi essencial selecionar um corpus de trabalho que oferecesse contextos de uso de linguagem autêntica, no sentido de investigar a sua função comunicativa. Para tanto, optamos por trabalhar com tirinhas do Armandinho, para representação de mas em língua portuguesa (Alexandre Beck) e Haiopeis para a análise contrastiva com a PM aber em língua alemã (Thomas Siemensen). Alguns dos quesitos orientadores para a escolha das tirinhas do Armandinho foram: ser um gênero textual com linguagem acessível; a sua grande circulação e crescente popularidade 
nos veículos de informação; oferecer um contexto visual e linguístico para a interpretação das PMs; as críticas sociais.

Assim, além da linguagem, as tirinhas do Armandinho foram selecionadas por serem espaços para manifestação de crítica social, carregadas de ironia e humor, para provocar efeitos de sentido. Marcuschi (2008, p. 149) afirma que o trabalho com gêneros engloba a análise do texto e do discurso para realizar uma descrição da língua e da sociedade. O gênero, portanto, não pode ser tratado independentemente da realidade social e das atividades humanas.

$O$ gênero textual das tirinhas se caracteriza por ser um texto curto, de estrutura em formato retangular, vertical ou horizontal, com um ou mais quadrinhos contendo diálogos curtos, com personagens icônicos, e desfecho imprevisto (LOPES, 2017, p. 33). De acordo com Santos (2002), tirinhas são definidas como uma forma de comunicação visual que se soma a elementos verbais para compor uma narrativa. A linguagem verbal e não verbal das tirinhas, composta por símbolos, imagens, expressões e personagens, oferece, portanto, uma rica conjuntura para interação entre os interlocutores, que também envolve os leitores e, contextos para a compreensão e interpretação das PMs.

A análise foi desenvolvida com foco em três parâmetros: a investigação das implicaturas da PM dentro de contextos de uso específicos, ou seja, por meio dos estímulos linguísticos e visuais das histórias das tirinhas; a delimitação da função nuclear da PM mas, tendo em vista os exemplos contextualizados; a discussão acerca das diferenças semânticas e sintáticas da PM e da conjunção adversativa mas; uma análise contrastiva do equivalente funcional de mas modal em língua alemã, a PM aber, estabelecendo uma base de contraste com um idioma que possui uma classe gramatical de palavras modais definida. Tal investigação nos permitirá recuperar as estratégias comunicativas da PM mas, evidenciando a relevância da delimitação de uma classe de palavras modais no português brasileiro.

A metodologia se servirá, portanto, da análise de seis tirinhas, quatro em português e duas em alemão, que apresentam mas com função modal, como conjunção adversativa e, estabelecendo uma relação com a 
classe de palavras de PMs em língua alemã, com o exemplo de aber modal e homônimo. Com essa investigação contrastiva temos a intenção principal de reforçar a importância de estudos inclusivos para palavras modalizadoras em nosso repertório linguístico.

\section{Análise}

Nesta seção apresentaremos as análises da função de mas como PM e conjunção adversativa (homônimo não modal) e, no intuito de estabelecer relações de equivalente funcional com um idioma que possui uma classe de palavras de PMs estabelecida, realizaremos uma investigação constrastiva com a PM aber de língua alemã. Tais análises são realizadas por meio de um corpus composto por seis tirinhas, divididos em duas subseções, cada uma com três insumos referentes ao uso de mas PM, mas homônimo e a PM aber em alemão.

As investigações desenvolvidas nessa seção procuram estabelecer uma relação contrastiva da função modal de mas, no sentido de levantar hipóteses acerca de seu uso dentro de contextos específicos, assim como questionar acerca da necessidade de uma adequação de classificação nas gramáticas de língua portuguesa. Os resultados levantados neste estudo são introdutórios, no entanto, abrem espaço para a discussão da relevância desses elementos modais para a comunicação em língua portuguesa.

\subsection{Análise 1}

Apresentamos nesta subseção a investigação acerca da função modal de mas, por meio da análise contrastiva com um corpus de três tirinhas, dois em língua portuguesa (imagem 1 e 2) com a ocorrência de mas (PM e conjunção) e um em língua alemã, contendo a PM aber (imagem 3).

A primeira tirinha (imagem 1) discute o racismo em uma abordagem policial, na qual o oficial, ao pedir a nota fiscal, questiona se as bicicletas 
pertenciam às duas crianças. A denúncia ao racismo é evidenciada pelo autor através da diferente reação dos dois personagens. Armandinho, o menino de pele branca, se mostra surpreso e indignado, enquanto a menina de pele negra, aparentemente acostumada com a situação, entrega a nota fiscal, não demonstrando a mesma indignação de Armandinho, mas talvez apenas tristeza, como podemos averiguar a seguir:
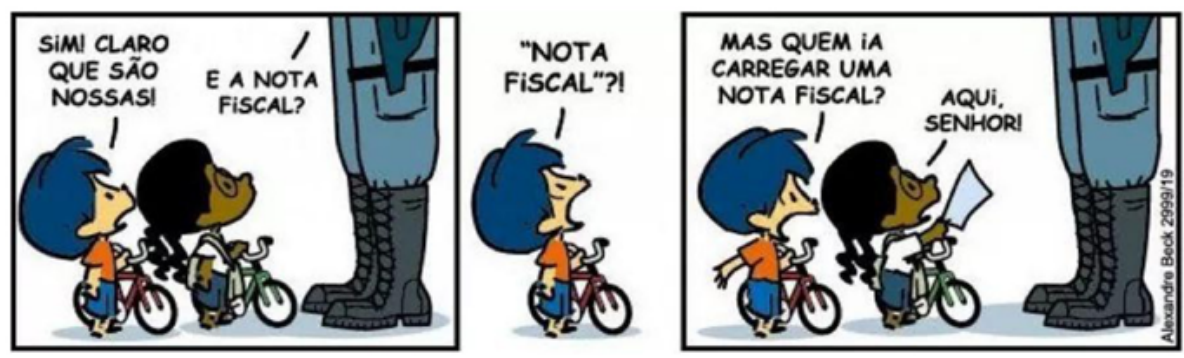

Imagem 1. Tirinha com o uso de mas como PM

Fonte: Beck (2020)

A surpresa e indignação de Armandinho pode ser reconhecida pela linguagem verbal e não-verbal: com a expressão gestual (braços para trás, olhos estalados e boca aberta); com o uso de mas no início da oração, “Mas quem ia carregar uma nota fiscal?". Nesse sentido, mas é o elemento linguístico que desempenha a função de indicar o efeito de surpresa em relação a um determinado ato ilocutório. Segundo Aquino e Arantes (2020, p. 181), o uso modal de mas não se limita apenas à expressão de espanto com o que está sendo enunciado, mas serve também para antecipar um conteúdo proposicional que os interlocutores compartilham ou acreditam compartilhar. Logo, ao utilizar a PM mas, o falante negocia inferências entre interlocutores que seriam, nesse caso, além dos personagens da tirinha, o próprio leitor.

6 Disponível em: https://www.facebook.com/tirasarmandinho/

Confluência. Rio de Janeiro: Liceu Literário Português, n. 60, p. 373-399, jan.-jun. 2021 
No exemplo dessa tirinha, o falante expressa, portanto, a sua surpresa em decorrência do pedido incomum do policial, no entanto, ele também ressalta que tal sentimento deveria ser compartilhado por todos, ou seja, todos sabem ou deveriam saber que a fala do oficial é incoerente, pois ninguém carrega notas fiscais dos produtos que compraram. O comportamento do policial parece, de fato, surpreendente e contraditório, especialmente para uma criança branca, mas a compreensão da mensagem da tirinha depende do reconhecimento do racismo por parte do leitor, que é evidenciado pelo uso da PM mas.

Nesse sentido, a PM mas, além de ter a função de indicar uma quebra de expectativa, traz pistas contextuais que auxiliam o leitor a interpretar a ironia da mensagem, isto é, a situação deveria surpreender, mas infelizmente não é o que acontece na história. Assim, para interpretar o conteúdo enunciativo do texto, é preciso reconhecer a intenção comunicativa do falante através da função comunicativa da PM mas, que se difere em diversos aspectos de seu homônimo não modal, como podemos observar por meio da análise da segunda tirinha (imagem 2).

A tirinha apresentada abaixo, com diálogo entre os personagens Pudim e Armandinho, faz referência às discussões acerca do isolamento social, causado pela pandemia de Covid-19, que fez com que muitas pessoas deixassem seus postos de trabalho e ficassem em casa, para conter a disseminação do vírus e achatar a curva de contaminação da população, visando evitar o colapso dos sistemas de saúde:
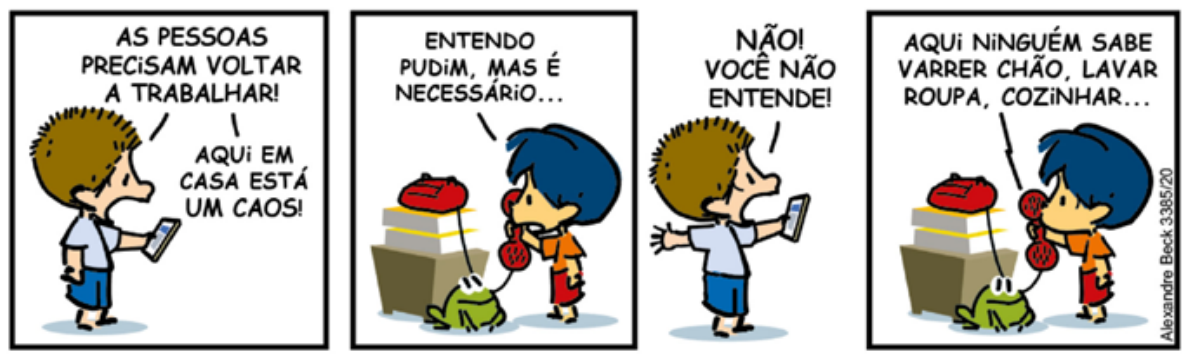

Imagem 2. Tirinha com o uso de mas como conjunção adversativa Fonte: Beck (2020) 
No primeiro quadrinho, Pudim, apoiado na justificativa que a sua casa está um caos, afirma que as pessoas precisam voltar a trabalhar, se referindo, como consta no último quadrinho, aos funcionários que realizam tarefas domésticas. Armandinho apresenta, então, um argumento para contestar a opinião do amigo, e para isso, utiliza a conjunção adversativa mas. $\mathrm{Na}$ oração do segundo quadrinho, mas tem a função de ligar duas informações contrastantes, isto é, os dois argumentos acerca do isolamento social: voltar a trabalhar e a importância do isolamento. Na oração "Entendo, mas é necessário", mas liga, portanto, dois itens lexicais, entendo (eu entendo o seu ponto de vista) e necessário (no entanto, o isolamento é necessário), tendo, assim, a função de indicar um contraste entre os elementos e informações da oração.

Consequentemente, podemos evidenciar que as funções de mas modal e conjunção apresentam uma diferença delimitadora essencial. Enquanto a PM mas não tem ligação com nenhum item lexical específico, ou seja, tem escopo na frase toda, a conjunção tem a função principal de ligar itens lexicais ou sentenças contrastantes. A compreensão da PM mas na primeira tirinha (imagem 1) depende, portanto, de uma investigação contextual que vai além do conteúdo da oração, possibilitando reconhecer a atitude e intenção do falante e as expectativas do ouvinte, que no caso do primeiro exemplo, representa uma quebra dessa expectativa, culminando na reação de surpresa do personagem.

Assim, as PMs não são elementos de ligação, como é o caso das conjunções, mas sim meios retóricos complexos essenciais para a negociação de sentidos entre os interlocutores. Segundo Diewald (2013, p. 22), as PMs introduzem implicações, suposições e alusões de maneira implícita, e a riqueza de suas funções comunicativas e retóricas advém desse potencial. Além disso, outro indicador pode estar atrelado à posição dos elementos na oração, isto é, a PM mas ocorre no início da frase e não é separada por vírgulas, já mas como conjunção é posicionada entre as orações contrastantes e é separada por vírgula, obedecendo a regra gramatical para o uso de conjunções (CASTILHO, 2016, p. 337 - 338). 
A partir da consideração desses exemplos podemos, portanto, evidenciar diferenças relevantes entre os usos de mas modal e não modal, levantando hipóteses acerca da necessidade de uma adequação gramatical desses elementos em duas classes de palavras distintas. Nesse sentido, uma relação semelhante entre homônimos pode ser observada na classificação das PMs alemãs, o que corrobora com o pressuposto de existência das PMs também no português.

No sentido de investigar os equivalentes funcionais da PM mas em português, apresentamos a seguir uma breve análise da PM aber, que será exemplificada com base na tirinha Haiopeis do autor Thomas Siemensen:
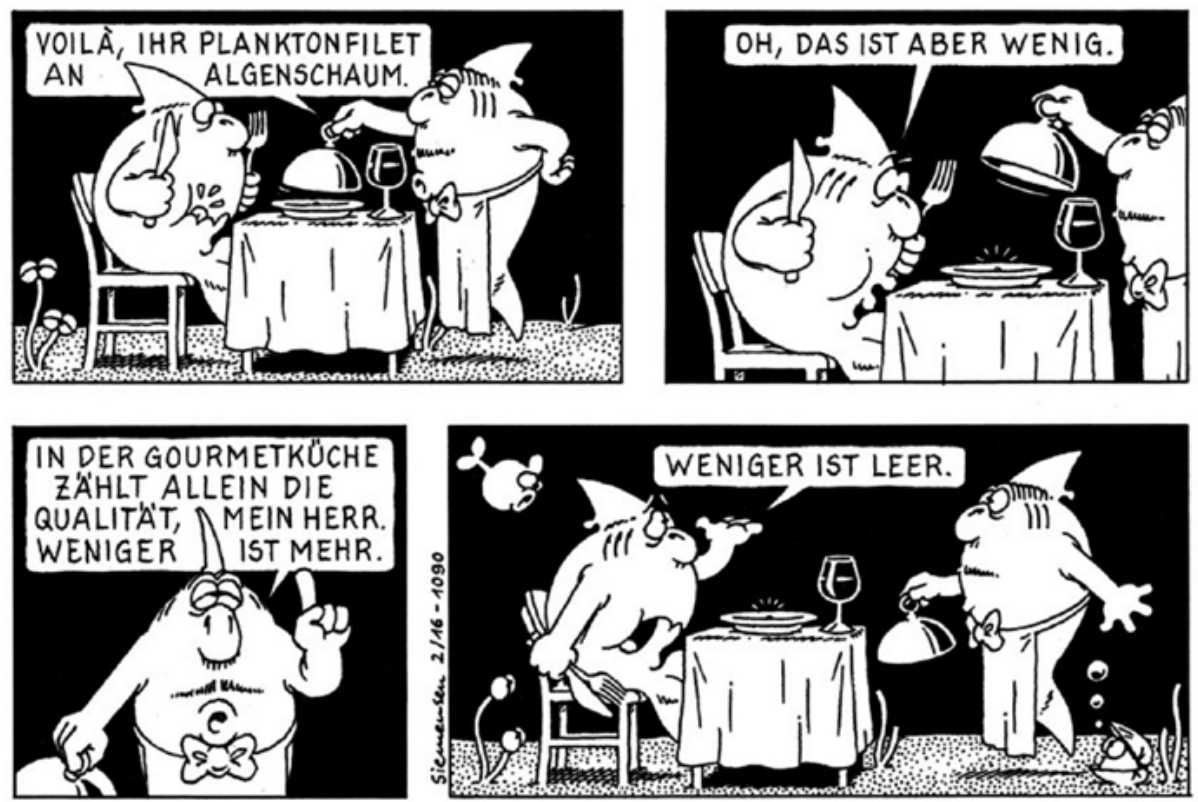

Imagem 3. Tirinha com o uso de aber como PM

Fonte: Siemensen $(2016)^{7}$

7 Disponível em https://www.siemensen-cartoons.de/blog/

Confluência. Rio de Janeiro: Liceu Literário Português, n. 60, p. 373-399, jan.-jun. 2021 
Na situação apresentada na imagem 3, o garçom entrega o prato ao cliente, que se surpreende ao ver a pouca quantidade de comida. Tal surpresa, ou até indignação, pode ser evidenciada pela observação da imagem, ou seja, seus olhos arregalados e postura inclinada, assim como pelos aspectos linguísticos na oração, “Oh, das ist aber wenig!” (“Oh, mas isso é muito pouco!”). Nesse contexto, o emprego de aber indica uma surpresa e quebra de expectativa do locutor, como na primeira tirinha apresentada neste trabalho (imagem 1).

Em ambos os casos, as partículas possibilitam que o falante acentue a intenção contida em seu enunciado, estabelecendo estratégias comunicativas, negociando o significado com o interlocutor. Assim, tanto a PM mas, como a PM aber, apresentam a função de indicar o efeito de surpresa ou quebra de expectativa com relação a um determinado ato ilocutório, antecipando um conteúdo proposicional que os interlocutores compartilham, ou acreditam compartilhar. Na primeira tirinha, a PM mas oferece pistas contextuais que auxiliam a interpretação da reação à fala incoerente do policial. Já a PM aber indica uma quebra de expectativa com relação à quantidade de comida que, segundo a percepção de um tubarão esfomeado, deveria ser muito maior.

De acordo com as características delimitadoras apontadas por Aquino (2020, p. 141), as PMs alemãs desempenham funções nucleares na comunicação, que ocorrem em todos os seus contextos de uso. A PM aber tem a função de indicar que a realidade é diferente da esperada. A quebra de expectativa está relacionada à extensão dos fatos (HENTSCHEL; WEYDT, 2013, p. 286), ou seja, no exemplo apresentado acima, a surpresa está vinculada ao fato não apenas do prato conter pouca comida, mas também que a quantidade é muito menor do que seria o esperado. Além disso, as PMs apresentam uma restrição de posicionamento, aparecendo apenas no campo central (Mittelfeld) da oração (entre rema e tema), característica que a diferencia de seu homônimo, também conjunção, como foi discutido anteriormente no arcabouço teórico.

Defendemos, portanto, que tanto a PM mas, como a PM aber, apresentam características delimitadoras semelhantes. No que tange a sua função comunicativa, ambas indicam uma quebra de expectativa e 
antecipam um conteúdo proposicional que os interlocutores compartilham. Com relação às questões estruturais, nas duas línguas as conjunções são separadas por vírgula e ligam elementos da oração, enquanto as PMs não são separadas por vírgula, ocorrem ou no início (mas), ou na posição central (aber) e tem escopo na oração toda.

Para melhor estabelecer as relações contrastivas e validar as hipóteses levantadas acerca da relação entre mas modal e conjunção, e entre os equivalentes funcionais em alemão, apresentamos na próxima seção a análise de outras três tirinhas em língua portuguesa e alemã.

\subsection{Análise 2}

$\mathrm{Na}$ segunda subseção apresentamos três tirinhas para análise contrastiva com a língua alemã, com as ocorrências de mas modal (imagem 4), mas como conjunção (imagem 5) e da PM aber (imagem 6).

A tirinha abaixo (imagem 4) retrata uma cerimônia de casamento, com o pronunciamento oficial da união matrimonial entre duas pessoas, um homem e uma mulher. O terceiro quadrinho contém o foco do humor crítico da tirinha, no qual o personagem Armandinho, ao escutar a declaração do ministrante da cerimônia, "E eu vos declaro, marido e mulher!", se espanta com a nova designação atribuída à noiva, questionando se o status "mulher" era apenas concedido através do ritual do casamento, como é possível observar a seguir:
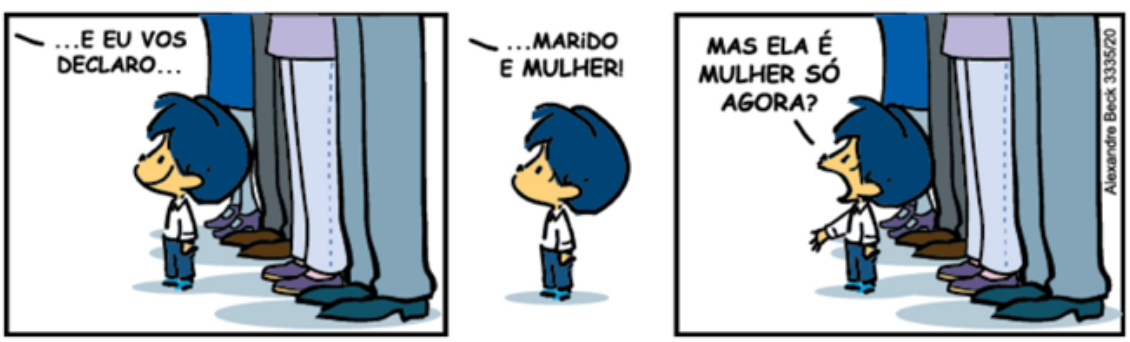

Imagem 4. Tirinha com o uso de mas como PM

Fonte: Beck (2020)

Confluência. Rio de Janeiro: Liceu Literário Português, n. 60, p. 373-399, jan.-jun. 2021 
Nota-se, mais uma vez, a importância do contexto e da interação entre os elementos visuais e linguísticos (BATISTA, 2008, p. 47), para a compreensão de sentido vinculado às PMs. O espanto do personagem é demonstrado pelo seu semblante surpreso, com olhos arregalados, boca completamente aberta e com o braço estendido com a mão para cima, assim como pelo uso da PM mas em: “Mas ela é mulher só agora?". Assim, a PM mas, neste caso, como na primeira tirinha, carrega a função de apontar uma quebra de expectativa por meio da reação de surpresa a um enunciado anterior.

$\mathrm{O}$ autor utiliza novamente da ironia para questionar situações cotidianas que, na verdade, deveriam causar espanto, tanto nos personagens, como nos leitores. No entanto, nos dois casos, apenas o garotinho, com menos experiência com os costumes sociais, parece se incomodar com casos de racismo (imagem 1) e de machismo (imagem 4). Assim, uso da PM mas, nas duas ocorrências, relaciona o enunciado a informações contextuais anteriores, permitindo-nos pressupor que a frustração com tais acontecimentos deveria ser compartilhada pelos interlocutores, como é a expectativa de Armandinho, evidenciada pelo uso da PM mas.

No sentido de compreender e negociar as informações da tirinha, é preciso, portanto, reconhecer a intenção e função comunicativa da PM mas, em cada contexto. Como discutimos na seção anterior, as funções de mas modal e o seu homônimo, se diferem em diversos aspectos, como podemos averiguar por meio do exemplo apresentado na quinta tirinha a seguir:
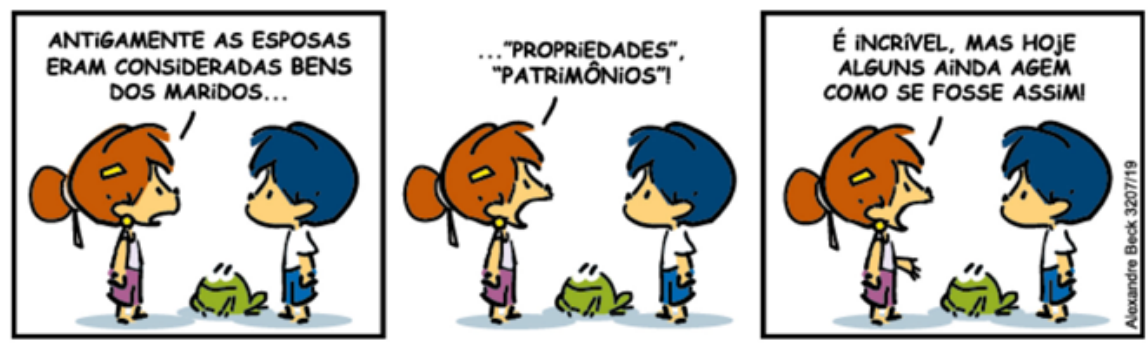

Imagem 5. Tirinha com o uso de mas como conjunção adversativa Fonte: Beck (2020) 
A tirinha apresenta o desabafo de uma personagem que reflete sobre as questões de gênero nas tradições culturais do casamento, indagando que percepções machistas e adversas (mulher ser vista como propriedade dos maridos), que ocorriam no passado, ainda estão presentes na sociedade atual. No terceiro quadrinho, a menina inicia a frase com "É incrível, mas (...)", dando indicações de contradição e insatisfação acerca das informações apresentadas nos dois primeiros quadrinhos.

A conjunção adversativa mas apresenta, nesse contexto, as mesmas características delimitadoras discutidas anteriormente: é precedida por vírgula na oração que a antecede e tem a função principal de ligar duas orações contrastantes, isto é, "é incrível" (que as mulheres sejam tratadas como propriedade), e "até hoje alguns agem como se fosse assim". De acordo com ABREU (2003, p.132), "adversativa é a oração que exprime oposição, contradizendo uma expectativa criada pela oração anterior." Assim, a contradição é explícita no último quadrinho, no qual o uso de mas indica que, ao contrário do que deveria acontecer, algumas pessoas ainda mantêm, nos dias de hoje, o mesmo pensamento arcaico que era considerado comum em outras épocas, apesar de não concordar com o padrão na sociedade moderna.

A análise das funções de mas nos exemplos das imagens 4 e 5 compactuam com as encontradas na seção anterior (4.1), isto é, que o uso modal e não modal possui funções semânticas e sintáticas distintas, ainda que as tirinhas compartilhem temáticas similares. A função comunicativa da PM mas e a distinção entre a conjunção adversativa encontra equivalentes na PM aber. Mesmo com algumas diferenças estruturais, as PMs em português e alemão apresentam uma função nuclear semelhante, ou seja, de indicar surpresa e quebra de expectativa no ambiente cognitivo de seus interlocutores, como podemos observar na tirinha em alemão a seguir: 

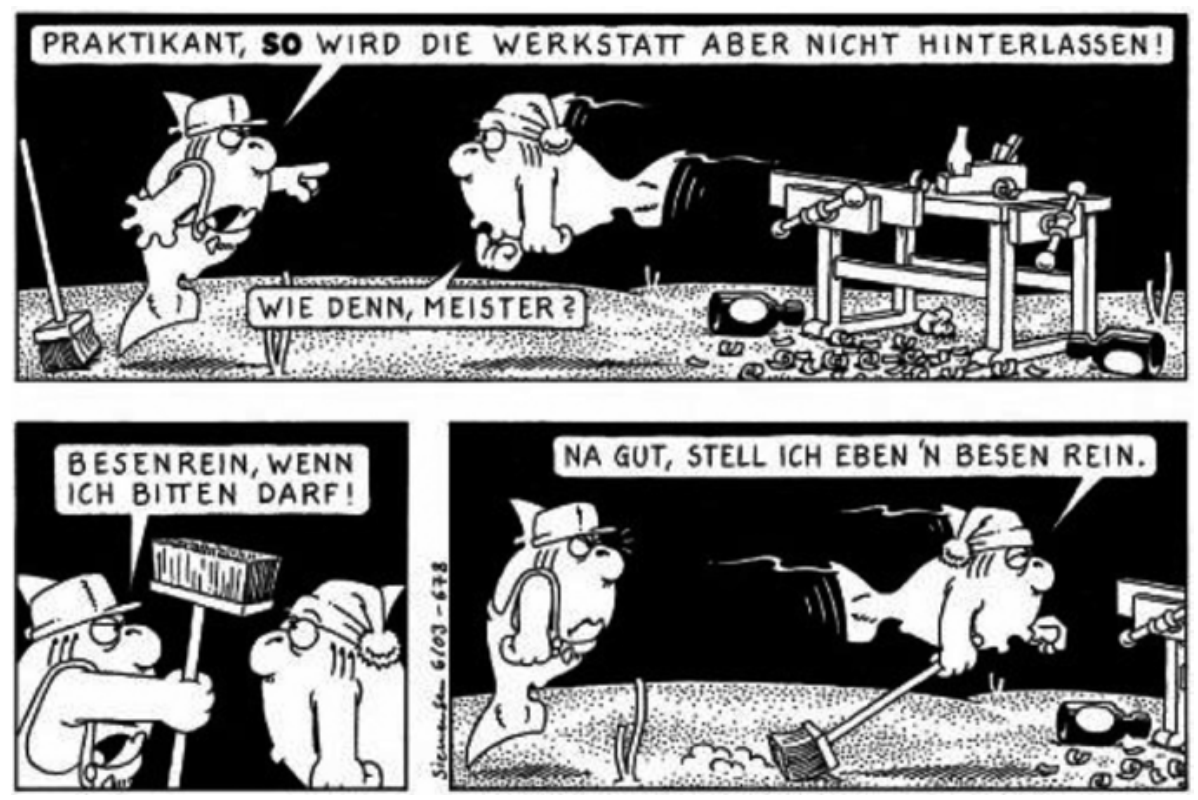

Imagem 6. Tirinha com o uso de aber como PM

Fonte: Siemensen (2003)

No primeiro quadrinho, é apresentada uma conversa entre dois personagens que estão em uma oficina. O tubarão de boné, aparentemente o chefe, ao ver o estado desorganizado em que se encontra a estação de trabalho, diz, "Praktikant, so wird die Werkstatt aber nicht hinterlassen!" ("Estagiário, mas você não pode deixar a oficina assim!"). O locutor, ao empregar a PM aber, nesse contexto, tem a intenção de evidenciar que houve uma quebra de expetativa com relação à organização do local e ao trabalho que o estagiário deveria ter realizado, destacando que tal situação não poderia, de forma alguma, permanecer, exigindo uma atitude por parte do interlocutor.

De acordo com AQUINO (2017, p. 67), as PMs funcionam como ferramentas gerando implicaturas fortes, com a redução do esforço despendido para alcançar grandes efeitos contextuais. No exemplo acima, a PM aber possibilita que o falante acentue a intenção contida em seu 
enunciado (a oficina não pode ficar desarrumada), estabelecendo estratégias comunicativas, negociando o significado com o interlocutor (ele precisa reagir imediatamente) de maneira clara e eficiente.

Nesse sentido, a PM aber, assim como a PM mas, tem a função de indicar uma quebra de expectativa com relação a uma determinada situação, trazendo à tona um conteúdo proposicional que os interlocutores compartilham, ou deveriam compartilhar. Tanto na tirinha 4 como na tirinha 6, as PMs apontam uma quebra de expectativa com relação a um contexto recuperável por meio de uma situação ou enunciado anterior, no qual os locutores indicam que o interlocutor necessita saber ou perceber que algo, não está de acordo com as suas expectativas, e exige uma atitude ou resposta por parte do ouvinte.

Com os resultados das análises contrastivas desenvolvidas nessa seção, podemos levantar algumas hipóteses principais acerca das diferenças comunicativas e sintáticas entre mas como PM e conjunção, além de evidenciar semelhanças entre as PMs em língua alemã e portuguesa, indicando a necessidade de uma adequação de classificação dessas palavras modais em português brasileiro. A principal diferença entre mas modal e homônimo parece ser a sua função na oração, uma vez que, nos exemplos analisados, mas modal expressa quebras de expectativas através da reação de surpresa, e não de contrastar informações nas orações, como é o caso das conjunções.

No entanto, foi possível notar que mas como PM e como conjunção compartilham algumas características básicas. Nos exemplos analisados ambas vinculam informações contraditórias, não obstante, essa contradição está nas conjunções a nível do texto, e as PMs introduzem implicações no ambiente cognitivo dos interlocutores, sendo meios retóricos mais complexos. Nesse sentido, as PMs brasileiras, assim como em alemão (ABRAHAM, 1991, p. 210), parecem derivar diacronicamente de elementos lexicais homônimos através da perda de complexidade semântica, mas ganho de complexidade pragmática. Argumentamos, assim, que o português brasileiro apresenta palavras modais com características delimitadoras distintas de seus 
homônimos, no entanto, mais investigações precisam ser desenvolvidas para comprovar teoricamente tal alegação.

\section{Conclusão}

Nesse artigo propomos uma investigação contrastiva, a fim de refletir acerca da necessidade de uma classificação adequada do uso modal de mas no português brasileiro. No sentido de identificar a função modal de mas, de delimitar as diferenças semânticas e sintáticas entre a PM e seu homônimo e estabelecer uma base de contraste com um idioma que possui uma classe de palavras de PM definida, o estudo foi desenvolvido por meio dos insumos verbais e não verbais de seis tirinhas em língua portuguesa e alemã. Tal investigação permitiu a recuperação das estratégias comunicativas da PM mas, evidenciando a relevância acerca da compreensão do uso de palavras modais no português brasileiro.

Com relação à função comunicativa nuclear da PM mas, identificamos, nos dois exemplos analisados (tirinha 1 e 4), que ela indica uma quebra de expectativa e surpresa, trazendo à tona um conteúdo proposicional que os interlocutores compartilham, ou acreditam compartilhar. Assim, enquanto o seu homônimo, conjunção adversativa, tem a função de ligar, ou contrapor, informações a nível da frase, as PMs evidenciam as inferências contextualizadas a serem processadas, acessando o ambiente cognitivo dos interlocutores.

Portanto, o autor das tirinhas do Armandinho utiliza das PMs no sentido de abrir espaço para uma negociação de significados, implicando na necessidade do leitor compreender a sua intenção por meio da quebra de expectativa, que levaria a uma reflexão crítica acerca das realidades socioculturais discutidas. O uso de mas nesses exemplos parece indicar, portanto, que a língua portuguesa também apresenta uma classe de palavras modais, com funções modalizadoras e estruturas sintáticas únicas, e seu conhecimento e delimitação é essencial para a compreensão de estratégias comunicativas em língua portuguesa. 
Em língua alemã as PMs representam uma classe de palavras homogênea, com diversas características delimitadoras que as diferenciam do seu homônimo não modal. Assim com a PM mas, a PM aber tem a função de indicar que a realidade é diferente da esperada, permitindo que o falante acentue a intenção contida em seu enunciado, negociando o significado com o seu interlocutor. Com relação às questões estruturais, nas duas línguas as conjunções são separadas por vírgula e ligam elementos da oração, enquanto as PMs não são separadas por vírgula, ocorrem ou no início (mas), ou no campo central (aber) e tem escopo na oração toda. Logo, mesmo com algumas diferenças estruturais, as palavras modais nos dois idiomas apresentam características delimitadoras semelhantes.

Concluímos, dessa forma, que as hipóteses levantadas nesse trabalho evidenciam a importância de pesquisas inclusivas que questionem e reflitam acerca da adequação da classificação de palavras modais como mas em gramáticas de língua portuguesa, sobretudo porque as PMs são meios retóricos para comunicar uma mensagem eficiente e concreta entre indivíduos envolvidos no processo interpretativo. É preciso, portanto, investir em um quadro de descrição semântico, pragmático e sintático extensivo do português brasileiro, para que se reconheça a força comunicativa das partículas modais portuguesas.

\section{Referências}

ABRAHAM, Werner. Discourse particles in German: how does their illocutive force come about? In: ABRAHAM, Werner. (Ed.). Discourse particles: descriptive and theoretical investigations on the logical, syntactic, and pragmatic properties of discourse particles in German. Amsterdam: Johns Benjamins, 1991. p. 203-252.

ABRAHAM, Werner; LEISS, Elisabeth. Modality and Theory of Mind Elements Across Languages. Berlin: Mouton de Gruyter, 2012. 
ABREU, Antônio Suárez. Gramática Mínima para o domínio da língua padrão. Cotia, SP: Ateliê Editorial, 2003. 351 p.

AQUINO, Marceli. A força comunicativa das partículas modais alemãs no ensino de línguas. Diálogo das Letras, Pau dos Ferros, v. 1, n. 2, p. 103-115, 2012.

AQUINO, Marceli. O esforço de processamento das partículas modais doch e wohl em tarefas de pós-edição: uma investigação processual no par linguístico alemão/português. 2016. 231 f. Tese (Doutorado em Estudos Linguísticos) - Faculdade de Letras, Universidade Federal de Minas Gerais, Belo Horizonte, 2016.

AQUINO, Marceli. O questionário como ferramenta de ensino de partículas modais alemãs. Pandaemonium Germanicum, São Paulo, v. 20, n. 32, p. 156-179, 2017.

AQUINO, Marceli. A tradução da partícula modal wohl para o português: uma investigação do esforço de processamento de participantes brasileiros e alemães. Revista Cadernos de Tradução, Florianópolis, v. 38, n.3, p. 352 - 374, 2018.

AQUINO, Marceli. O ensino das partículas modais alemãs: estratégias didáticas em ALE. Revista Brasileira de Linguística Aplicada, Belo Horizonte, v. 20, n. 1, p. 131-161, 2020.

AQUINO, Marceli; ARANTES, Poliana Coeli Costa. Partículas modais em alemão e seus equivalentes funcionais em português brasileiro: proposta de análise e classificação para o uso. Pandaemonium Germanicum, São Paulo, v. 23, n. 40 , p. 166-190, 2020.

ARANTES, Poliana Coeli Costa. Análise pragmática do uso de partículas modais em alemão e em português: incentivo às abordagens metalinguísticas no ensino de alemão em contexto universitário In: UPHOFF, Dörthe et al. $O$ ensino de alemão em contexto universitário: modalidades, desafios e perspectivas. São Paulo: Humanitas, 2017. p. 123-144. 
BECK, Alexandre. Armandinho. Disponível em: <https://www.facebook. com/tirasarmandinho/>. Acesso em: 13 mar 2020.

AUSTIN, John Langshaw. How to Do Things With Words. Cambridge (Mass.). Paperback: Harvard University Press, 1962. 168 p.

BATISTA, Adriana Danielski. Os implícitos nas histórias em quadrinhos. 2008. 87 f. Dissertação (Mestrado) - Faculdade de Letras, Pontifícia Universidade Católica do Rio Grande do Sul, Porto Alegre, 2008.

CASTILHO, Ataliba Teixeira de. Nova Gramática do Português Brasileiro. São Paulo: Editora Contexto, 2016. 768 p.

DEGAND, Liesbeth; PIETRANDREA, Paola; CORNILliE, Bert (eds.). Discourse markers and modal particles. Categorization and description. Amsterdam/Philadelphia: John Benjamins, 2013. 220 p.

DIEWALD, Gabriele. Discourse Particles and Modal Particles as Grammatical Elements. In: FISCHER, Kerstin. Approaches to Discourse Particles. Amsterdam: Elsevier, 2006. p. 403-426.

DIEWALD, Gabriele. Same same but different. Modal particles, discourse markers and the art (and purpose) of categorization. In: DEGAND, Liesbeth; PIETRANDREA, Paola; CORNILLIE, Bert (org.). Discourse markers and modal particles. Categorization and description. Amsterdam \& Philadelphia: John Benjamins, 2013. p. 19-46.

DUDEN. Grammatik der deutschen Gegenwartssprache. Mannheim: Bibliographisches Institut, 2016. 1341 p.

FISCHER, Kerstin; ALM, Maria. A radical construction grammar perspective on the modal particle-discourse particle distinction. In: DEGAND, Liesbeth; PIETRANDREA, Paola; CORNILLIE, Bert (org.). Discourse markers and modal particles. Categorization and description. Amsterdam \& Philadelphia: John Benjamins, 2013. p. 47-88. 
FRANCO, António. Descrição linguística das partículas modais no português e no alemão. Coimbra: Coimbra Editora, 1991. 448 p.

HENTSCHEL, Elke; WEYDT, Harald. Handbuch der Deutschen Grammatik. 4. ed. Berlin: De Gruyter, 2013. 472 p.

JOHNEN, Thomas. Aí como partícula modal do português. In: $1^{\circ}$ CONGRESSO INTERNACIONAL DA ASSOCIAÇÃO BRASILEIRA DE LINGUÍSTICA, vol. 2, 1997, Salvador, BA. Anais... Salvador: Instituto de Letras da Universidade Federal da Bahia, 1997. p. 1 -5.

KRÖLL, Heinz. Die Ortsadverbien im Portugiesischen unter besonderer Berücksichtigung ihrer Verwendung in der modernen Umgangssprache. Wiesbaden: Mainzer Romanistische Arbeiten, 1968. 244 p.

LEISS, Elisabeth. Epistemicity, evidentiality, and Theory of Mind (ToM). In: ABRAHAM, Werner. Modality and theory of mind: elements across languages. Berlin: De Gruyter, 2012. p. 37-66.

LOPES, Magda Aparecida. As tirinhas de Mafalda sob a ótica de Bakhtin no processo ensino-aprendizagem. Revista X, Curitiba, v.12, n.3, p. 47-62, 2017. MARCUSCHI, Luiz Antonio. Produção textual, análise de gêneros e compreensão. São Paulo: Parábola Editorial, 2008. 295 p.

PALMER, Frank Robert. Mood and Modality. Cambridge: Cambridge University Press, 1986. 200 p.

POLENZ, Peter von. Deutsche Satzsemantik: Grundbegriffe des Zwischenden-Zeilen-Lebens. Berlin/New York, de Gruyter, 1985. 389 p.

RAMOS, Rui Lima. As partículas modais como co-indicadores ilocutórios: o caso das perguntas retóricas. In: XV ENCONTRO NACIONAL DA ASSOCIAÇÃO PORTUGUESA DE LINGUÍSTICA, 2000, Minho, Portugal. Anais... Minho: Universidade do Minho, 2000. p. 1-20. 
SAID ALI, Manuel. Meios de Expressão e Alterações Semânticas, Rio de Janeiro: Livraria Francisco Alves, 1930. 159 p.

SANTOS, Roberto Elísio dos. Para reler os quadrinhos Disney: linguagem, evolução e análise de HQs. São Paulo: Paulinas, 2002. 320 p.

SCHMIDT-RADEFELDT, Jürgen. Partículas discursivas e interacionais no português e no espanhol em contraste com o alemão. In: SCHMIDTRADEFELDT, Jürgen (org.). Semiótica e linguística portuguesa e românica: Homenagem a José Gonçalo de Carvalho. Tübingen: Narr, 1993. p. 63-78.

SIEMENSEN, Thomas. Haiopeis. Disponível em: $<$ https://www.siemensencartoons.de/blog/>. Acesso em 13 mar 2020.

SPERBER, Dan.; WILSON, Deirdre. Teoria da Relevância. Linguagem em (Dis)curso, Tubarão, v. 5, p. 221-268, 2005.

TRAUGOTT, Elizabeth Closs. Discussion article: Discourse markers, modal particles and contrastive analysis, synchronic and diachronic. Catalan Journal of Linguistics. Barcelona, v.6, p. 139-157, 2007.

VILELA, Mário. Gramática da língua portuguesa: gramática da palavra, gramática da frase, gramática do texto/discurso. Coimbra: Almedina, 1999. $381 \mathrm{p}$.

VILELA, Mário.; KOCH, Ingedore Villaça. Gramática da Língua Portuguesa: gramática da palavra, gramática da frase, gramática do texto/ discurso. Coimbra: Almedina, 2001. 566 p.

WALTEREIT, Richard. Modal particles and their functional equivalents: a speech-act theoretic approach. Journal of Pragmatics. Lancaster, v. 33, n. 9, p. 1391-1417, 2001.

WALTEREIT, Richard. Different functions, different histories. Modal particles and discourse markers from a diachronic point of view. Catalan Journal of Linguistics, Barcelona, v. 6, p. 61-80, 2007. 
WELKER, Herbert. As partículas modais no alemão e no português e as equivalências de aber, eben, etwa e vielleicht. 1990. 205 f. Dissertação (Mestrado) - Departamento de Linguística, Universidade de Brasília, Brasília. 1990. 